\title{
FAKTOR-FAKTOR YANG MEMPENGARUHI TERHADAP TIMBULNYA ACNE VULGARIS (JERAWAT) PADA REMAJA DI SMAN 1 PELANGIRAN KABUPATEN INDRAGIRI HILIR TAHUN 2018
}

\author{
Asbullah $^{1}$ Putri Wulandini $^{2}$, Yulia Febrianita ${ }^{3}$ \\ Mahasiswa Keperawatan Universtas Riau \\ Email asbullah1195@gmail.com
}

\begin{abstract}
ABSTRAK
Acne vulgaris meruakan peradangan / penyakit kulit menahun pilosebasea terdapat papul, komedo, , nodul, pustul, dan kista. remaja wanita umur 14-17 tahun dan . remaja pria umur 16-19 tahun. faktor umur, faktor pemakaian kosmetik dan faktor makanan adalah faktor-faktor yamg mempengaruhi terhadap timbulnya acne vulgaris.Tujuan dari penelitian ini untuk mengetahui faktor-faktor yang mempengaruhi terhadap timbulnya acne vulgaris (jerawat) pada remaja di SMAN 1 Pelangiran Tahun 2018. Desain penelitian yang digunakan adalah cross sectional, tempat penelitian yaitu di SMAN 1 Pelangiran .Populasi dalam peneliti ini adalah seluruh siswa/i SMAN 1 Pelangiran sebanyak 177 orang. Sampel 122 responden. Sampel pada penelitian ini di ambil dengan mengunakan metode cluster sampling. Data yang digunakan data primer, instrument penelitian berupa kuesioner. Data dianalisa secara univariat dan bivariat. Hasil penelitian diperoleh bahwa Mayoritas berada pada umur 17 tahun yaitu sebanyak 47 orang (38,5\%).Mayoritas siswa/i yang mengalami terhadap timbulnya Acne Vulgaris (jerawat) pada remaja di SMAN 1 Pelangiran memiliki kebiasaan tidak memakai sebanyak 83 orang (68,0\%). Mayoritas siswa/i yang mengalami terhadap timbulnya acne vulgaris (jerawat) pada remaja di SMAN 1 Pelangiran kabupaten Indragiri Hilir memiliki kebiasaan mengkonsumsi makanan tidak baik sebanyak 99 orang ( 81,1\%). Diharapkan kepada siswa/i untuk meningkatkan lagi pengetahuan tentang masalah penyebab jerawat dan dapat meningkatkan prilaku kebersihan diri agar mengurangi kejadian Acne Vulgaris, dan lebih peduli dengan kesehatan dengan penerapan pola hidup yang sehat sehingga membantunya agar dapat memilikii body image yang positif.
\end{abstract}

Kata kunci

: Remaja, Acne Vulgaris, Umur, pemakaian kosmetik, makanan

\begin{abstract}
Acne vulgaris is a chronic skin disease that occurs due to chronic inflammation of pilosebasea characterized by blackheads, papules, pustules, nodules and cysts in the predilection areas that are usually in the sebaceous glands such as face, chest and upper back. in adolescent acne incidence occurs with the age range 14-17 years in women, and in men the age range 16-19 years. factors influencing the occurrence of acne vulgaris is age factor, cosmetic usage factor and food factor. The purpose of this research is to know the factors that influence on the emergence of acne vulgaris (acne) in adolescents at SMAN 1 Pelangiran Year 2018. The research design used is cross sectional, where the research is in SMAN 1 Pelangiran. Population in this research is all student of SMAN 1 Pelangiran 177 people. Sample 122 respondents. The sample in this research is taken by using cluster sampling method. Data used primary data, research instrument in the form of questionnaire. Data were analyzed univariat and bivariate. The results of the study showed that the majority were at the age of 17 years, as many as 47 people (38.5\%). The majority of students who experienced the onset of Acne Vulgaris (acne) in adolescents at SMAN 1 Pelangiran had the habit of not using as many as 83 people (68,0\%). The majority of students who experienced the onset of acne vulgaris (acne) in adolescents at SMAN 1 Pelangiran Indragiri Hilir district has a habit of consuming bad food as much as 99 people (81.1\%). It is expected that students will improve their knowledge of acne causing problems and improve self-hygiene behaviors to reduce the incidence of Acne Vulgaris, and be more concerned with health with the adoption of a healthy lifestyle that helps them to have a positive body image.

Keywords : Teenagers, Acne Vulgaris, Age, use of cosmetics, food
\end{abstract}




\section{PENDAHULUAN}

Acne vulgaris adalah penyakit kulit kronis yang terjadi akibat peradangan menahun pilosebasea yang ditandai dengan adanya komedo, papul, pustul, nodul dan kista di area predileksinya yang biasanya pada kelenjar sebasea seperti wajah, dada dan punggung bagian atas. Acne memiliki konsekuensi medis dan psikologis yang bermakna meskipun tidak mengancam kehidupan. Efek negatif dari acne adalah jaringan parut permanen pada wajah, dada atau punggung, serta perasaan citra diri yang buruk, hambatan sosial dalam bergaul, depresi, dan kecemasan (Pujiastuti, 2012).

Pada remaja insiden acne terjadi dengan kisaran umur 14-17 tahun pada wanita, dan pada pria kisaran umur 16-19 tahun (Wasitaatmadja, 2009). Acne dikatakan hingga $80 \%$ populasi pada satu saat. Gambaran khas adalah timbul pada remaja, sering kali yang sedang mengalami tanda-tanda awal pubertas, dengan beragam lesi yang hilang timbul. Dapat ditemukan beberapa jenis kulit lesi (Bourke, 2011).

Insidensi tertinggi terdapat pada perempuan antara umur 14-17 tahun dan pada laki-laki antara umur 16-19 tahun. Tetapi dapat pula timbul pada usia di atas 40 tahun dan penyakit ini dapat pula menetap pada usia lanjut. $10 \%$ kasus didapat pada usia 30-40 tahun. Bentuk yang lebih berat dari acne terdapat pada kira-kira 3\% lakilaki lebih jarang pada perempuan (Rahmawati, 2012).

Berdasarkan faktor-faktor yang menyebabkan timbulnya acne vulgaris pada remaja menurut (Hardianti Hasan dkk, 2015) yaitu faktor umur yang terjadi pada usia dewasa muda pada umur 14-17 tahun pada wanita 16-19 pada pria adalah sebesar $80-100 \%$. Selanjutnya pada faktor kosmetik yang menjadi penyebab timbulnya acne vulgaris karena sering mengunakan jenis bedak/krim pada wajah. Kemudian yang terakhir adalah faktor makanan yang menjadi penyebab timbulnya acne vulgaris yaitu makanan yang tinggi lemak, makanan tinggi karbohidrat dan makanan tinggi yodium. Hal ini disebabkan menjelang dewasa tubuh mengalami berbagai penyesuaian fisik, sosial dan psikologi yang pada umumnya disebabkan oleh hormon dimana salah satunya adalah hormon androgen. Hormon androgen merupakan hormon yang berperan aktif dalam merangsang tubuh, kadar hormon androgen meningkat dan mencapai puncak pada umur 18-20 tahun (Winarno \& Ahnan, 2014).

Kosmetika dapat menyebabkan acne seperti bedak dasar (foundation), pelembab (moisturiser), krem penahan sinar matahari (sunscreen) dan krem malam, jika mengandung bahanbahan komedo genik. Bahan-bahan komedo genik seperti lanolin, petrolatum, minyak atsiri dan bahan kimia murni (asam oleik, butil stearat, lauril alkohol, bahan pewarna Drug dan Cosmetic (D\&C) biasanya terdapat pada krim-krim wajah. Untuk jenis bedak yang sering menyebabkan acne adalah bedak padat (Ramdani \& Sibero. 2015)

Menurut Afriyanti. R Nisa 2015 faktor-faktor yang mempengaruhi timbulnya acne vulgaris yaitu : Faktor Umur, Faktor Pemakaian Kosmetik, Faktor Makanan, Faktor Hormon. 
Menurut (Winarno dan Ahnan 2014). Faktor makanan yang buruk dapat memperparah timbulnya jerawat. Terdapat makanan tertentu yang memperberat Acne vulgaris. makanan tersebut antara lain adalah makanan tinggi lemak (gorengan, kacang, susu, keju, dan sejenisnya), makanan tinggi karbohidrat (makanan manis, coklat, dll), alkohol, makanan pedas, dan makanan tinggi yodium (garam). Lemak dalam makanan dapat mempertinggi kadar komposisi sebum (Rompas,2015).

Prevalensi acne pada masa remaja cuup tinggi, yaitu berkisar antara $47-90 \%$. Pada penelitian yang dilakukan di Brazil dari 2200 remaja laki-laki berusia 18 tahun didapatkan $76 \%$ menderita acne vulgaris. Sedangkan di Prancis dari 852 remaja berusia 12-25 tahun didapatkan 66,2 $\%$ menderita acne vulgaris. $\mathrm{Di}$ Indonesia sendiri berdasarkan penelitian yang dilakukan di kota Palembang, dari 5204 subjek didapatkan prevalensi umum acne vulgaris sebanyak 68,2\% (Primadani, 2015).

Dari survei dikawasan Asia Tenggara melaporkan kejadian terdapat $40-80 \%$ kasus jerawat, sedangkan di Indonesia, laporan kelompok studi dermatologi kosmetika Indonesia, menunjukkan terdapat $60 \%$ penderita jerawat pada tahun 2006 dan $80 \%$ pada tahun 2007 (Husna.2013)

Berdasarkan penelitian yang dilakukan oleh R.M Suryadi Tjekyan pada tahun 2009 di Palembang, dari 5204 responden dengan rincian lakilaki sebanyak 2459 responden dan perempuan 2745 responden di dapatkan yang menderita acne vulgaris pada laki-laki lebih tinggi yaitu sekitar $1940(54,7 \%)$ daripada perempuan yaitu sekitar 1607 $(45,3 \%)$.

Menurut hasil penelitian yang dilakukan oleh Dipta Wahyuning Astuti pada tahun 2011 di Semarang menunjukkan bahwa sebagian besar penderita menyukai makanan jenis kacang - kacangan (60\%).

Berdasarkan survei awal di SMAN 1 pelangiran didapatkan informasi bahwa dari 8 siswa/i berhasil diwawancarai yang mengalami jerawat. dua orang pada usia muda 14-16 tahun merasakan binti-binti kemerahan pada wajah. Dua orang dengan pola dan gaya hidup yang serba berkecukupan dalam hal makanan yang sering mengkonsumsi makanan tinggi lemak (gorengan, kacang,) makanan tinggi karbohidrat (makanan manis, makanan pedas,) dan makanan tinggi yodium (garam), Dan empat orang dengan pemakaian kosmetik yang sering berganti-ganti pembersih wajah ini juga merupakan salah satu faktor penyebab munculnya jerawat pada siswa/siswi yang ada di SMAN 1 Pelangiran.

Dari latar belakang di atas, maka peneliti tertarik untuk melakukan penelitian lebih lanjut tentang "Faktor-Faktor yang Mempengaruhi Terhadap Timbulnya Acne Vulgaris (Jerawat) Pada Remaja di SMAN 1 Pelangiran Kabupaten Indragiri Hilir Tahun 2018”.

Berdasarkan latar belakang diatas, yang menjadi perumusan masalah penelitian yaitu Bagaimana Faktor-Faktor yang mempengaruhi Terhadap timbulnya Acne Vulgaris ( jerawat ) pada remaja di SMAN 1 Pelangiran Kabupaten Indragiri Hilir Tahun 2018 ?

Tujuan penelitian Untuk Mengetahui Faktor-Faktor yang 
Mempengaruhi Terhadap Timbulnya Acne Vulgaris (jerawat) pada Remaja di SMAN 1 Pelangiran Kabupaten Indragiri Hilir Tahun 2018. Dimana tujuan khusus penelitian sebagai berikut Untuk mengetahui distribusi frekuensi Acne Vulgaris, berdasarkan umur, berdasarkan pemakaian kosmetik, berdasarkan makanan, faktor umur, faktor pemakaian kosmetik, faktor makanan berpengaruh terhadap timbulnya Acne Vulgaris di SMAN 1 Pelangiran Kabupaten Indragiri Hilir tahun 2018.

Hasil penelitian ini diharapkan dapat memperluas wawasan peneliti terutama dalam meneliti Faktor timbulnya Acne Vulgaris pada remaja. Diharapkan menambah pengetahuan bagi siswa/i SMAN 1 Pelangiran, khususnya tentang timbulnya acne vulgaris (jerawat) pada remaja dan cara pencegahan agar tidak terjadi kerusakan pada kulit, sehingga pihak sekolah dapat memberikan penyuluhan kesehatan tentang perawatan kulit. Hasil penelitian ini dapat menjadi referensi dan bahan masukan yang memungkinkan bagi peneliti yang akan datang dalam melakukan penelitian, khususnya yang berhubungan dengan masalah timbulnya acne vulgaris (jerawat) pada remaja pada usia sekolah.

\section{METODE PENELITIAN}

Dalam penelitian ini peneliti mengunakan jenis penelitian yang bersifat Korelasi dengan desain penelitian cross sectional, yang bertujuan untuk memperoleh informasi tentang faktor faktor yang mempengaruhi timbulnya Acne Vulgaris ( jerawat ) pada remaja di SMAN 1 Pelangiran Kabupaten Indragiri Hilir Tahun 2018 (Kundre, 2017). Populasi adalah seluruh objek atau subjek yang akan diteliti (Notoatmodjo, 2010). Populasi dalam penelitian ini adalah seluruh siswa/i SMAN 1 PELANGIRAN berjumlah 177 orang. Sampel atau subjek penelitian adalah bagian dari populasi yang kita inginkan (Riyanto, 2011). Sampel penelitian ini adalah siswa/i kelas X, XI dan XII SMAN 1 PELANGIRAN. Sampel pada penelitian ini adalah seluruh siswa/i, yang memiliki beberapa kriteria yang telah ditetapkan oleh peneliti, yaitu siswa/i yang berada pada kelas X, XI dan XII dengan jumlah keseluruhannya yaitu 122 siswa.

\section{HASIL DAN PEMBAHASAN}

Berdasarkan hasil penelitian yang dilakukan pada bulan Febuari 2018 terhadap 122 Responden tentang " Faktor-Faktor Yang Mempengaruhi Terhadap Timbulnya Acne Vulgaris ( Jerawat ) Pada Remaja Di SMAN 1 Pelangiran Kabupaten Indragiri Hilir Tahun 2018 " maka hasil penelitian disajikan dalam bentuk tabel distribusi frekuensi sebagai berikut

Tabel 3 
Distribusi Frekuensi Faktor - Faktor Yang Mempengaruhi Terhadap Timbulnya Acne Vulgaris Pada Remaja berdasarkan Kosmetik Di SMAN 1 Pelangiran Kabupaten Indragiri Hilir Tahun 2018

\begin{tabular}{|c|c|c|c|}
\hline No & Kosmetik & Jumlah & Persentase (\%) \\
\hline 1 & Memakai & $\mathbf{3 9}$ & $\mathbf{3 1 , 9 \%}$ \\
\hline 2 & Tidak memakai & $\mathbf{8 3}$ & $\mathbf{6 8 , 0 \%}$ \\
\hline \multicolumn{2}{|c|}{ Jumlah } & $\mathbf{1 2 2}$ & $\mathbf{1 0 0 \%}$ \\
\hline
\end{tabular}

Berdasarkan tabel 3 terlihat bahwa mayoritas siswa/i yang mengalami terhadap timbulnya Acne Vulgaris (Jerawat) pada remaja di SMAN 1
Pelangiran kabupaten indragiri Hilir memiliki kebiasaan tidak memakai sebanyak 83 orang $(68,0 \%)$

\section{Tabel 4}

Distribusi Frekuensi Faktor - Faktor Yang Mempengaruhi Terhadap Timbulnya Acne Vulgaris Pada Remaja berdasarkan Makanan Di SMAN 1 Pelangiran Kabupaten Indragiri Hilir Tahun 2018

\begin{tabular}{|c|c|c|c|}
\hline No & Makanan & Jumlah & Persentase (\%) \\
\hline 1 & Baik & $\mathbf{2 3}$ & $\mathbf{1 8 , 8 \%}$ \\
\hline 2 & Tidak Baik & $\mathbf{9 9}$ & $\mathbf{8 1 , 1 \%}$ \\
\hline \multicolumn{2}{|c|}{ Jumlah } & $\mathbf{1 2 2}$ & $\mathbf{1 0 0 \%}$ \\
\hline
\end{tabular}

Berdasarkan tabel 4 terlihat bahwa mayoritas siswa/i yang mengalami terhadap timbulnya acne vulgaris (jerawat) pad remaja di SMAN 1
Pelangiran kabupaten Indragiri Hilir memiliki kebiasaan mengkonsumsi makanan tidak baik sebanyak 99 orang $(81,1 \%)$.

Tabel 5

Distribusi Frekuensi Faktor - Faktor Yang Mempengaruhi Terhadap Timbulnya Acne Vulgaris Pada Remaja berdasarkan Acne Vulgaris Di SMAN 1 Pelangiran Kabupaten Indragiri Hilir

Tahun 2018

\begin{tabular}{|c|c|c|c|}
\hline No & Acne Vulgaris & Jumlah & Persentase (\%) \\
\hline 1 & Acne & 109 & $89,3 \%$ \\
\hline 2 & Tidak Acne & 13 & $10,6 \%$ \\
\hline \multicolumn{2}{|r|}{ Jumlah } & 122 & $100 \%$ \\
\hline
\end{tabular}

Berdasarkan tabel 5 terlihat bahwa mayoritas siswa/i yang mengalami terhadap timbulnya acne vulgaris (jerawat) pada remaja di SMAN 1 Pelangiran kabupaten Indragiri Hilir mengalami Acne sebanyak 109 orang $(89,3 \%)$. 


\section{A. Analisa Bivariat}

\section{Tabel 6}

Hubungan Faktor Umur Dengan Kejadian Acne Vulgaris

\begin{tabular}{|c|c|c|c|c|c|}
\hline & \multicolumn{2}{|c|}{ Umur Kejadian Acne } & P Value & $\mathrm{N}$ \\
\hline & & Mean & $\mathrm{SD}$ & \multirow{3}{*}{0,05} & 1 \\
\hline \multirow{2}{*}{$\begin{array}{c}\text { Kejadian } \\
\text { Acne }\end{array}$} & Acne & 17,46 & 0,660 & & 13 \\
\hline & $\begin{array}{l}\text { Tidak } \\
\text { Acne }\end{array}$ & 17,03 & 1,067 & & 109 \\
\hline
\end{tabular}

Dari $\mathrm{P}$ value $\leq 0,05$, berarti ada hubungan faktor umur dengan kejadian acne vulgaris.

Tabel 7

Hubungan Faktor Pemakaian Kosmetik Dengan Kejadian Acne Vulgaris

\begin{tabular}{|c|l|c|c|c|c|}
\hline \multicolumn{2}{|c|}{} & \multicolumn{2}{|c|}{ Pemakaian Kosmetik } & Total & $\begin{array}{c}\text { P } \\
\text { Value }\end{array}$ \\
\cline { 3 - 5 } \multicolumn{2}{|c|}{} & Memakai & $\begin{array}{c}\text { Tidak } \\
\text { Memakai }\end{array}$ & & \\
\cline { 1 - 4 } $\begin{array}{c}\text { Kejadian } \\
\text { Acne }\end{array}$ & Acne & 37 & 72 & 109 & \\
\cline { 2 - 5 } & $\begin{array}{l}\text { Tidak } \\
\text { Acne }\end{array}$ & 2 & 11 & 13 & \\
\hline \multicolumn{2}{|c|}{ Total } & 39 & 83 & 122 & \\
\hline
\end{tabular}

Dari $\mathrm{P}$ value 0,175 atau $\mathrm{P}$ value $>0,05$ jadi tidak ada hubungan faktor pemakaian

Tabel 8

Hubungan Faktor Makanan Dengan Kejadian Acne Vulgaris

\begin{tabular}{|c|c|c|c|c|c|}
\hline \multicolumn{2}{|c|}{} & \multicolumn{2}{|c|}{ Faktor Makanan } & Total & P Value \\
\cline { 3 - 5 } \multicolumn{2}{|c|}{} & $\begin{array}{c}\text { Tidak } \\
\text { Baik }\end{array}$ & Baik & & \\
\hline \multirow{3}{*}{$\begin{array}{c}\text { Kejadian } \\
\text { Acne }\end{array}$} & Acne & 91 & 18 & 109 & \multirow{2}{*}{0,05} \\
\cline { 2 - 5 } & $\begin{array}{l}\text { Tidak } \\
\text { Acne }\end{array}$ & 8 & 5 & 13 & \\
\hline \multicolumn{2}{|c|}{ Total } & 99 & 23 & 122 & \\
\hline
\end{tabular}


Dari P Value $\leq 0,05$, berarti ada hubungan faktor makanan dengan kejadian acne vulgaris.

\section{Pembahasan}

Faktor - $\quad$ Faktor Yang Mempengaruhi Terhadap Timbulnya Acne Vulgaris Pada Remaja berdasarkan Acne Vulgaris Berdasarkan tabel 5 terlihat bahwa siswa/i yang mengalami terhadap timbulnya acne vulgaris (jerawat) pada remaja di SMAN 1 Pelangiran kabupaten Indragiri Hilir mengalami Acne sebanyak 109 orang $(89,3 \%)$.

Hal ini sesuai pendapat Sofia L \& Kurniawaty E (2015), salah satu penyakit yang banyak dijumpai secara global pada remaja dan dewasa muda adalah jerawat atau Acne vulgaris. acne vulgaris adalah suatu kelainan dari folikel rambut dan kelenjar sebasea yang tersering di jumpai pada wajah,dada dan punggung.

Di indonesia acne vulgaris merupakan penyakit kulit yang umum terjadi sekitar 85 hingga 100 persen selama hidup seseorang. Acne vulgaris sering dijumpai pada wanita yang berusia 14-17 tahun dan pada pria berusia 16-19 tahun. (Sofia L \& Kurniawaty E, 2015).

Dengan demikian peneliti berasumsi acne vulgaris pada remaja merupakan penyakit umum yang terjadi pada seseorang dan penyakit ini sering di jumpai pada seseorang dalam usia pada wanita 14-16 tahun dan pada pria 16-19 tahun.

Faktor-Faktor Yang Mempengaruhi Terhadap Timbulnya Acne vulgaris pada remaja berdasarkan umur

Berdasarkan tabel 1 terlihat bahwa responden mayoritas berada pada Umur 17 tahun yaitu sebanyak 47 orang $(38,5 \%)$.

Pada remaja insiden acne terjadi dengan kisaran umur 14-17 tahun pada wanita, dan pada pria kisaran umur 16-
19 tahun (Wasitaatmadja, 2009). Dari hasil survey dikawasan asia tenggara hampir setiap orang pernah mengalami acne vulgaris dan biasa dimulai ketika pubertas, terdapat $40-80 \%$ kasus acne vulgaris. prevelansi tertinggi yaitu pada umur 14-17 tahun, dimana pada wanita berkisar 83-85 \% dan pada pria yaitu pada umur 16-19 tahun berkisar 95100\% (Afriyanti RN, 2015).

Hal ini sesuai menurut pendapat (Ramdani Resti,2015) puncak insiden pada wanita dijumpai pada usia 14-17 tahun sedangkan pada pria antara usia 16-19 tahun. Hampir 85\% anak SMA yang berusia 15-18 tahun, baik laki-laki maupun perempuan menderita acne.

Dengan demikian peneliti berasumsi bahwa Pada remaja insiden acne terjadi dengan kisaran umur 14-17 tahun pada wanita, dan pada pria kisaran umur 16-19 tahun. remaja sedang mengalami tandatanda awal pubertas dan dengan beragam lesi yang hilang timbul. Faktor-Faktor Yang Mempengaruhi Terhadap Timbulnya Acne vulgaris pada remaja berdasarkan Pemakaian kosmetik

Berdasarkan tabel 3 terlihat bahwa mayoritas siswa/i yang mengalami terhadap timbulnya Acne Vulgaris (Jerawat) pada remaja di SMAN 1 Pelangiran kabupaten indragiri Hilir memiliki kebiasaan tidak memakai sebanyak 83 orang $(68,0 \%)$.

Dengan demikian peneliti berasumsi bahwa siswa/i SMAN N 1 Pelangiran kebanyakan tidak cocok dalam pengunaan pemakaian kosmetik dan tahu dampak dari pemakaian kosmetik akan menimbulkan jerawat, sehingga kebiasaan siswa/i memiliki kebiasaan tidak memakai pengunaan kosmetik. Sekarang banyak dokter kulit, dokter yang kaya sampai dengan yang miskin bisa berobat kedokter Maka 
tidak berhubungan. Kosmetik yang digunakan terjamin karena dikeluarkan dari spesialis-spesialis ahli kulit. Malahan yang tidak mengunakan kosmetik yang menimbulkan jerawat karena hormon di usia remaja yang menyebabkan jerawat muncul. Sedangkan remaja yang berobat ke dokter hormon dan kosmetiknya di sesuaikan dengan dokternya.

Kosmetika dapat menyebabkan Hal ini tidak sesuai dengan hasil penelitian responden bahwa mayoritas siswa/i yang mengalami timbulnya jerawat di SMPN 1 Kampar timur memiliki kebiasaaan mengunakan kosmetik sebanyak 40 orang $(56,6 \%)$.

\section{Faktor-Faktor \\ Mempengaruhi \\ Yang \\ Timbulnya remaja berdasarkan makanan}

Berdasarkan tabel 4.4 terlihat bahwa mayoritas siswa/i yang mengalami terhadap timbulnya acne vulgaris (jerawat) pada remaja di SMAN 1 Pelangiran kabupaten Indragiri Hilir memiliki kebiasaan mengkonsumsi makanan tidak baik sebanyak 99 orang $(81,1 \%)$.

Menurut Afriyanti RN, (2015) terdapat maknan tertentu yang memperberat Acne vulgaris, makanan tersebut antara lain adalah makanan tinggi lemak (gorengan,kacang,susu,keju dan sejenisnya), makanan tinggi karbonhidrat (makanan manis,coklat dll), alkohol, makanan pedas, dan makanan tinggi yodum (garam).

pola makan adalah gambaran mengenai macam, jumlah, dan komposisi bahan makanan yang dimakan tiap hari oleh satu orang yang merupakan ciri khas dari suatu kelompok masyarakat tertentu (Diwanta,2013). hal ini sesuai pendapat menurut (Rompas SS, 2015) bahwa Terdapat makanan tertentu yang memperberat Acne vulgaris. makanan tersebut antara lain adalah makanan tinggi lemak (gorengan, kacang, susu, keju, dan sejenisnya), makanan tinggi karbohidrat (makanan manis, coklat, dll), alkohol, makanan pedas, dan makanan tinggi yodium (garam). Lemak dalam makanan dapat mempertinggi kadar komposisi sebum.

Dengan demikian peneliti berasumsi pola makan yang buruk seperti makanan tinggi lemak, makanan tinggi karbonhidrat, makanan tinggi yodium (garam) adalah jenis makanan pemicu timbulnya jerawat.

\section{Hubungan Faktor Umur Dengan Kejadian Acne Vulgaris}

hasil penelitian tabel 4.6 Faktor Umur dengan kejadian Acne dari P Value $\leq$ 0,05 , ada hubungan faktor umur dengan kejadian acne vulgaris.

Dengan demikian peneliti berasumsi menjelang dewasa tubuh mengalami berbagai penyesuaian fisik, sosial dan psikologi yang pada umumnya disebabkan oleh hormon dimana salah satunya adalah hormon progesteron. Penigkatan hormon testosteron yang dapat memicu jerawat. Pada wanita, tingginya kadar progesteron bbeberapa saat sebelum menstruasi dan naiknya kadar testerone menjelang mestruasi akan mengaktifkan kelenjar minyak dan menyebabkan sumbatan pada pori-pori kulit. Keadaan ini membuat bakteri acne dapat berkembangbiak dan menyebabkan peradangan pada kulit dalam bentuk jerawat.

\section{Hubungan Faktor Pemakaian Kosmetik Dengan Kejadian Acne Vulgaris}

Hasil penelitian pada tabel 4.7 faktor pemakaian kosmetik dengan kejadian acne dari $\mathrm{P}$ value 0,175 , Tidak ada 
hubungan faktor pemakaian kosmetik dengan kejadian acne vulgaris.

Hal ini tidak sesuai menurut pendapat (Resti R, 2015) bahwa pemakaian bahan kosmetik tertentu dalam jangka waktu yang lama akan dapat menyebabkan timbulnya jerawat. Bahan yang dapat dan sering menyebabkan acne vulgaris ini terdapat pada berbagai krim muka seperti bedak, bedak dasar (foundation), pelembab (moisturiser), dan krim penahan sinar matahari (suncreen).

Menurut sumber Suryadi, (2008) bahwa ada dua efek atau pengaruh kosmetik terhadap kulit, yaitu efek positif dan negatif. Tentu saja yang di harapkan adalah efek positifnya, sedangkan efek negatifnya tidak diinginkan karena dapat menyebabkan kelainan-kelainan kulit yang terjadi antara lain disebabkan oleh cara pemakaian kosmetik yang salah atau berlebihan, pengolahan kosmetik yang kurang baik, serta pengunaan bahanbahan aktif dalam kosmetik yang tidak tepat.

Berdasarkan hasil wawancara salah satu seorang guru karena siswa/i belum pantas mengunakan kosmetik di usia remaja dan pihak sekolah memberlakukan peraturan melarang pemakaian kosmetik agar pandangan masyarakat tidak jelek terhadap siswa/i di sekolah. Peneliti berasumsi karena siswa/i tahu dampak dalam pengunaan kosmetik akan menimbulkan jerawat sehingga siswa/i kabanyakan tidak memakai dalam pengunaan kosmetik.

\section{Hubungan Faktor Makanan Dengan} Kejadian Acne Vulgaris

Hasil penelitian pada tabel 4.8 faktor makanan dengan kejadian acne dari $\mathrm{P}$ Value $\leq 0,05$, ada hubungan faktor makanan dengan kejadian acne vulgaris.

Terdapat makanan tertentu yang memperberat Acne vulgaris. makanan tersebut antara lain adalah makanan tinggi lemak (gorengan, kacang, susu, keju, dan sejenisnya), makanan tinggi karbohidrat (makanan manis, coklat, dll), alkohol, makanan pedas, dan makanan tinggi yodium (garam). Lemak dalam makanan dapat mempertinggi kadar komposisi sebum (Rompas SS,2015).

Hal ini sesuai dengan pendapat winarno \& ahnan (2014), bahwa faktor pemicu untuk timbulnya jerawat adalah Pola makan yang buruk dapat memperparah timbulnya jerawat. Sejauh ini, jerawat (acne vulgaris) dinyatakan berhubungan dengan indeks glisemik suatu makanan.

Dengan demikian peneliti berasumsi faktor pemicu untuk timbulnya jerawat adalah Pola makan yang buruk dan dapat memperparah timbulnya jerawat seperti makanan tinggi lemak, makanan tinggi karbonhidrat, makanan tinggi yodium (garam).

\section{KESIMPULAN}

Berdasarkan hasil penelitian yang dilakukan pada bulan Febuari 2018 terhadap 122 Responden tentang “ Faktor-Faktor Yang Mempengaruhi Terhadap Timbulnya Acne Vulgaris ( Jerawat ) Pada Remaja Di SMAN 1 Pelangiran Kabupaten Indragiri Hilir Tahun 2018 " maka dapat disimpulkan sebagai berikut:

1. Mayoritas siswa/i yang Acne sebanyak 109 orang $(89,3 \%)$.

2. Mayoritas berada pada umur 17 tahun yaitu sebanyak 47 orang $(38,5 \%)$.

3. Mayoritas siswa/i yang mengalami terhadap timbulnya Acne Vulgaris (jerawat) pada remaja di SMAN 1 Pelangiran memiliki kebiasaan tidak memakai sebanyak 83 orang ( $68,0 \%$ )

4. Mayoritas siswa/i yang mengalami terhadap timbulnya 
acne vulgaris (jerawat) pada remaja di SMAN 1 Pelangiran

kabupaten Indragiri Hilir

memiliki kebiasaan

mengkonsumsi makanan tidak

baik sebanyak 99 orang (

$81,1 \%)$

5. Dari $P$ value $\leq 0,05$ berarti ada hubungan faktor umur dengan kejadian acne vulgaris.

6. Dari $\mathrm{P}$ value 0,175 atau $\mathrm{P}$ value $>0,05$ jadi tidak ada hubungan faktor pemakaian kosmetik dengan kejadian acne vulgaris.

7. Dari $P$ Value $\leq 0,05$, berarti ada hubungan faktor makanan dengan kejadian acne vulgaris. 